Aword of caution, however, is exemplified by one of our patients who had proven adenocarcinoma of the right lung and a positron emission tomographic scan that demonstrated bilateral hilar and mediastinal uptake suggestive of nodal metastasis. EBUS biopsy of both the right and left paratracheal and hilar areas demonstrated malignant cells when a biopsy was acquired from the right side. On the basis of this finding, the patient was recommended not to have additional interventional therapy, but rather to have a regimen of chemotherapy and radiotherapy. When we were consulted for a second opinion. On review of her studies, it was our feeling that she did not have strong evidence of metastatic disease. Surgical intervention with upper lobectomy and removal of 18 hilar and mediastinal lymph nodes revealed no positive nodal metastasis on microscopic pathologic review.

On retrospective review of the original EBUS study, there were both malignant cells and lymphoid cells within the specimen. Our feeling, retrospectively, was that a false-positive report suggesting metastatic disease resulted from the needle passing through the node and into the lung, thus obtaining pulmonary carcinoma cells compared with nodal carcinoma cells. This may lead to a potential misdiagnosis and misstaging, resulting from a false-positive result of metastatic carcinoma to the lymph nodes, and a nonoperative or different therapeutic recommendation.

Raymond A. Dieter, Jr, MD

George B. Kuzycz, MD

DuPage Medical Group Glen Ellyn, Ill

\footnotetext{
Reference

1. Lee B, Kletsman E, Rutledge JR, Korst RT. Utility of endobronchial ultrasound-guided mediastinal lymph node biopsy in patients with non-small cell lung cancer. J Thorac Cardiovasc Surg. 2012; 143:585-90.
}

http://dx.doi.org/10.1016/ j.jtcvs.2012.08.017

\section{THE BEST SURGICAL STRATEGY IN PATIENTS WITH LEFT MAIN STEM DISEASE \\ To the Editor:}

We read with great interest the article by Murzi and colleagues ${ }^{1}$ regarding the best surgical management in coronary artery disease patients with left main stem disease undergoing surgical revascularization. The authors present a high quality observational study comparing off-pump coronary artery bypass grafting (CABG) with on-pump $\mathrm{CABG}$, in a large cohort of consecutive patients with left main stem disease over a period of 15 years.

Actually, 2 randomized studies had already addressed this question: the Veterans Affairs Randomized On/Off Bypass (ROOBY) trial ${ }^{2}$ and the CABG Off or On Pump Revascularization Study (CORONARY) trial. ${ }^{3}$

The CORONARY trial ${ }^{3}$ is the largest multinational, prospective, randomized trial to date, involving 4,752 patients, conducted in 19 countries at 79 centers. More than $20 \%$ of enrolled patients showed significant left main stem disease. At 30 days after randomization, there was no significant difference between off-pump and on-pump CABG with respect to the rate of death, nonfatal myocardial infarction, nonfatal stroke, or renal failure requiring dialysis. Subgroup analyses showed that there was no significant difference concerning the coprimary outcome in patients $(\mathrm{n}=1001)$ with left main stem disease at 1 month after randomization (off-pump $\mathrm{n}=514$ patients, on-pump $n=487$; hazard ratio, $0.80 ; 95 \%$ confidence interval, $0.55-1.16 ; P=.24)$. The sure-tobe-forthcoming midterm and longterm primary outcomes results will influence the interpretation of the CORONARY trial.

The ROOBY trial, ${ }^{2}$ which involved 2,203 male patients in 18 Veterans Affairs medical centers demonstrated no advantage for off-pump CABG either at 30 days or at 1 year after surgery. There was no significant difference between the 2 cohorts concerning the primary short-term (ie, before discharge or within 30 days after surgery) composite outcome of death or postoperative major morbidity (ie, reoperation, new mechanical support, cardiac arrest, coma, stroke, or renal failure requiring dialysis). However, at 1-year follow-up, patients in the beatingheart technique group experienced worse composite outcomes (ie, death from any cause, repeat revascularization procedure, or nonfatal myocardial infarction) than did patients in the on-pump group. The rate of graft patency was significantly lower in the off-pump group than in the on-pump group $(82.6 \%$ vs $87.8 \% ; P<.01)$ at 1 year and this accounted for most of the difference in late composite outcomes between the 2 groups. Notably, Shroyer et $\mathrm{al}^{2}$ state that their ROOBY trial conclusions can be generalized to subgroups of high risk candidates, among them patients with left stem main disease.

We have only 1 question for Murzi and colleagues ${ }^{1}$ regarding their surgical management in the off-pump group: Might the $0 \%$ stroke result found in the off-pump CABG group have been the result of using total arterial revascularization and aortic "notouch" techniques? Both of those methods decrease significantly the incidence of stroke after CABG, particularly in patients with aortic atherosclerosis.

\section{Jamil Hajj-Chahine, MD \\ Christophe Jayle, MD, PhD \\ Pierre Corbi, MD, PhD \\ Department of Cardiothoracic \\ Surgery \\ University Hospital of Poitiers \\ Poitiers, France}

\section{References}

1. Murzi M, Caputo M, Aresu G, Duggan S, Miceli A, Glauber M, et al. On-pump and off-pump coronary artery bypass grafting in patients with left main stem disease: a propensity score analysis. J Thorac Cardiovasc Surg. 2012;143:1382-8.

2. Shroyer AL, Grover FL, Hattler B, Collins JF, McDonald GO, Kozora E, et al, Veterans Affairs 
Randomized On/Off Bypass (ROOBY) Study Group. On-pump versus off-pump coronary-artery bypass surgery. N Engl J Med. 2009;361:1827-37.

3. Lamy A, Devereaux PJ, Prabhakaran D Taggart DP, Hu S, Paolasso E, et al. Off-pump or on-pump coronary-artery bypass grafting at 30 days. N Engl J Med. 2012;366:1489-97.

http://dx.doi.org/10.1016/ j.jtcvs.2012.06.058

\section{Reply to the Editor:}

We thank Chahine and colleagues for their letter in response to our article discussing on-pump and offpump coronary artery bypass grafting in patients with left main stem disease. ${ }^{1}$ We never claimed that offpump coronary artery bypass surgery is the best strategy for patients with left main disease. Our conclusion was that "off-pump coronary artery surgery in patients with left main stem disease is a safe procedure that will reduce morbidity and mortality and similar long-term survival compared with conventional on-pump revascularization."

We are aware of the results of the 2 recent randomized studies referred to in the letter. The Coronary Artery Bypass Grafting Off or On Pump Revascularization trial ${ }^{2}$ did not demonstrate any substantial difference between the 2 techniques, and the study concluded that "There was no significant difference between off-pump and on-pump CABG with respect to the 30-day rate of death, myocardial infarction, stroke, or renal failure requiring dialysis." Those authors go on to say, "The use of off-pump CABG resulted in reduced rates of transfusion, reoperation for perioperative bleeding, respiratory complications, and acute kidney injury but also resulted in an increased risk of early revascularization." 2 However, investigators in the Veterans Affairs Randomized On/Off Bypass trial $^{3}$ concluded that the results of surgeries performed offpump were inferior to conventional on-pump coronary artery bypass graft surgery. That study, as pointed out in a recent editorial, ${ }^{4}$ had several major limitations. More than $70 \%$ of eligible patients (ie, scheduled for urgent or elective coronary artery bypass grafting) were excluded because of clinical reservations of the surgical team or small target vessels. This suggests inexperience on the part of surgeons in the trial, who were required to have performed just 20 off-pump coronary artery bypass procedures (OPCAB) to participate. Conversion to on-pump coronary artery bypass, which is known to increase morbidity and mortality, occurred in $>12 \%$ of cases, much greater than the $1 \%$ to $3 \%$ reported by centers specializing in OPCAB. In the OPCAB group, $>50 \%$ of patients received red blood cell transfusions, which contrasts with the $30 \%$ in previous randomized trials. Finally, only a small minority of the studied population were high-risk patients, a group more likely to benefit from OPCAB.

At the Bristol Heart Institute we have been performing OPCAB surgery for $>17$ years. We are a high volume center, with OPCAB accounting for $70 \%$ of all coronary procedures. We recognize that OPCAB surgery is a technically demanding procedure that should be performed in a high volume center to obtain optimal outcome. We think that OPCAB is a technique for the many and not the few (both surgeons and patients) but only with structured training and supervision in the right environment. ${ }^{4}$

Finally, with regard to the specific question on the incidence of stroke, in our article we reported a similar $0.4 \%$ incidence of transient cerebrovascular accident (CVA) in both groups and $0 \%$ and $0.9 \%$ of permanent CVA in the off-pump and on-pump groups, respectively. With off-pump procedures it is possible to minimize manipulation of the aorta because there is no requirement for cannulation when performing total arterial revascularization. However, in our series a majority of patients also received vein grafts that were anastomosed to the ascending aorta using a side bite exclusion clamp. The incidence of CVA was low regardless if patients were operated on using the on-pump or off-pump technique. We have no reason to believe that this information is inaccurate given that it was obtained from our institution's prospectively collected database. Permanent CVA is a clearly defined event that is most unlikely to have been missed by our clinicians.

\section{Gianni D. Angelini, MD Michele Murzi, MD Bristol Heart Institute University of Bristol Bristol, United Kingdom}

\section{References}

1. Murzi M, Caputo M, Aresu G, Duggan S, Miceli A, Glauber M, et al. On-pump and off-pump coronary artery bypass grafting in patients with left main stem disease: a propensity score analysis. J Thorac Cardiovasc Surg. 2012;143:1382-8.

2. Lamy A, Devereaux PJ, Prabhakaran D, Taggart DP, $\mathrm{Hu} \mathrm{S}$, Paolasso E, et al. Off-pump or on-pump coronary-artery bypass grafting at 30 days. $N$ Engl J Med. 2012;366:1489-97

3. Shroyer AL, Grover FL, Hattler B, Collins JF, McDonald GO, Kozora E, et al, Veterans Affairs Randomized On/Off Bypass (ROOBY) Study Group. On-pump versus off-pump coronary-artery bypass surgery. N Engl J Med. 2009;361:1827-37.

4. Patel N, Angelini GD. Off-pump coronary artery bypass grafting: for the many or the few? J Thorac Cardiovasc Surg. 2010;140:951-3.

$$
\begin{array}{r}
\text { http://dx.doi.org/10.1016/ } \\
\text { j.jtcvs.2012.07.042 }
\end{array}
$$

\section{VARIABLE ON TREATMENT PLATELET REACTIVITY IN CORONARY ARTERY BYPASS GRAFTING PATIENTS SUGGESTS THE NEED FOR PERIOPERATIVE PLATELET FUNCTION TESTING}

\section{To the Editor:}

With great interest we have read a recent article from Deja and colleagues ${ }^{1}$ on preoperative aspirin in an elective coronary artery bypass grafting population. The authors conducted a single-center, double-blind, randomized trial comparing its effects to placebo. The primary endpoints were more than $750 \mathrm{~mL}$ of bleeding during the first 12 hours postoperatively and 